\title{
ASTER DEM Based Studies for Geological Investigation around Singhbhum Shear Zone (SSZ) in Jharkhand, India
}

\author{
B.SINGH, J.DOWERAH \\ University Department of Geology, Ranchi University, Ranchi-834008, Jharkhand, India \\ Email: bsingh6029@gmail.com, jdowerah@gmail.com
}

\begin{abstract}
Singhbhum Shear Zone (SSZ) is a geologically rich belt with structures like faults and folds being the distinctive features. Due to these characteristics this area has been an important centre of studies since past few decades. With the advent of Remote Sensing and GIS, it has been possible to study and interprete geological setting of any area in the laboratory itself without even visiting the field again and again. The present study aims to investigate the geology of the SSZ from ASTER DEM by observing the elevation, aspect, texture, pattern etc of shaded relief images. This can prove to be an excellent supplementary information database for interpretations along with other data.
\end{abstract}

Keywords: RS-GIS, ASTER DEM, Singhbhum Shear Zone (SSZ), geological structure

\section{Introduction}

With the introduction of computer technologies the relationships between the map and map documentation is subjected to the GIS standards. However, the modern computer technologies may provide additional tools for geological mapping which may improve better agreement of determined geological units with the terrain topography. One of such tools is the Digital Elevation Model (DEM) which can serve both as information

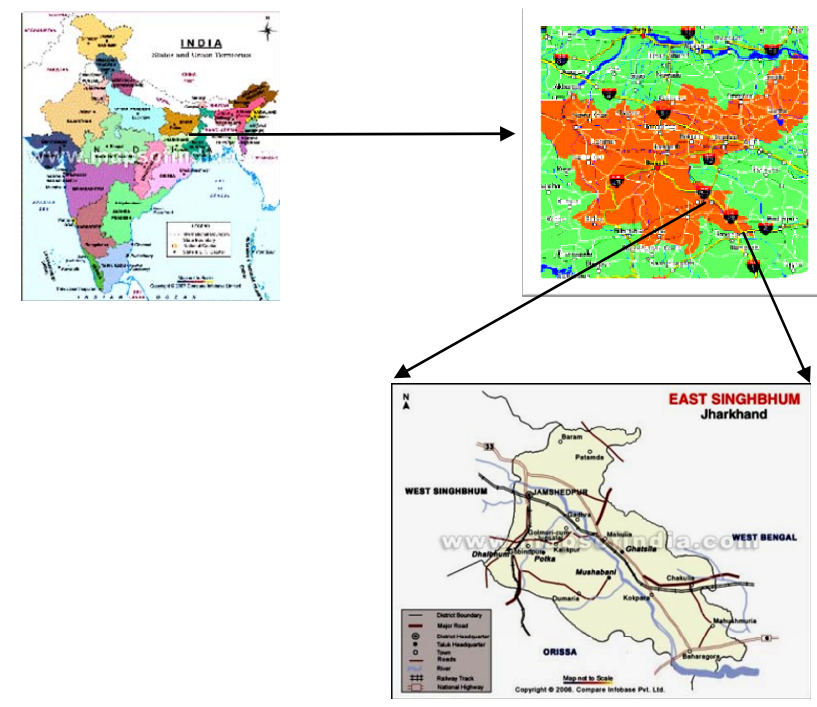

Figure 1. Location Map (source: www.mapsofindia.com) source for finding geological boundaries, controlling elevations, and at the same time play a role in preparation of the base map as well as various surficial thematic maps.( S. Ostaficzuk, 2005). A digital elevation model (DEM) is a digital representation of ground surface topography or terrain. It is used for many purposes like providing flood and landslide risk zone, highways and corridor selection including cut and fill estimation etc. These data are also good for geological interpretation particularly in terms of geomorphology, rock type and structure (Sarapirome et al. 2002).

SSZ is an arcuate belt which is one of the most well known mineral abundant zones in the country and extensive mineral exploration has been carried out in this zone since long. The study area falls in the SSZ and is extended between $22^{\circ} 41^{\prime} \mathrm{N}$ : $86^{\circ} 14^{\prime} \mathrm{E}$ and $22^{\circ} 28^{\prime} \mathrm{N}$ : $86^{\circ}$ $27 \mathrm{E}$ in the south east confined in the East Singhbhum district of Jharkhand (Figure 1).

\section{Materials and Methods}

\section{Data used: $\quad$ Software used: \\ ASTER DEM 1. ERDAS IMAGINE 9.1 \\ 2. Arc GIS 9.3}

The input data for the present study is ASTER DEM having $15 \mathrm{~m}$ resolution. The aspect mapping which may help in knowing the topographical and geological features is generated from the DEM in ArcGIS platform. A number of shaded relief images are also generated from the DEM having different azimuth, sun angle and vertical exaggeration. It is seen that different sun angle and 


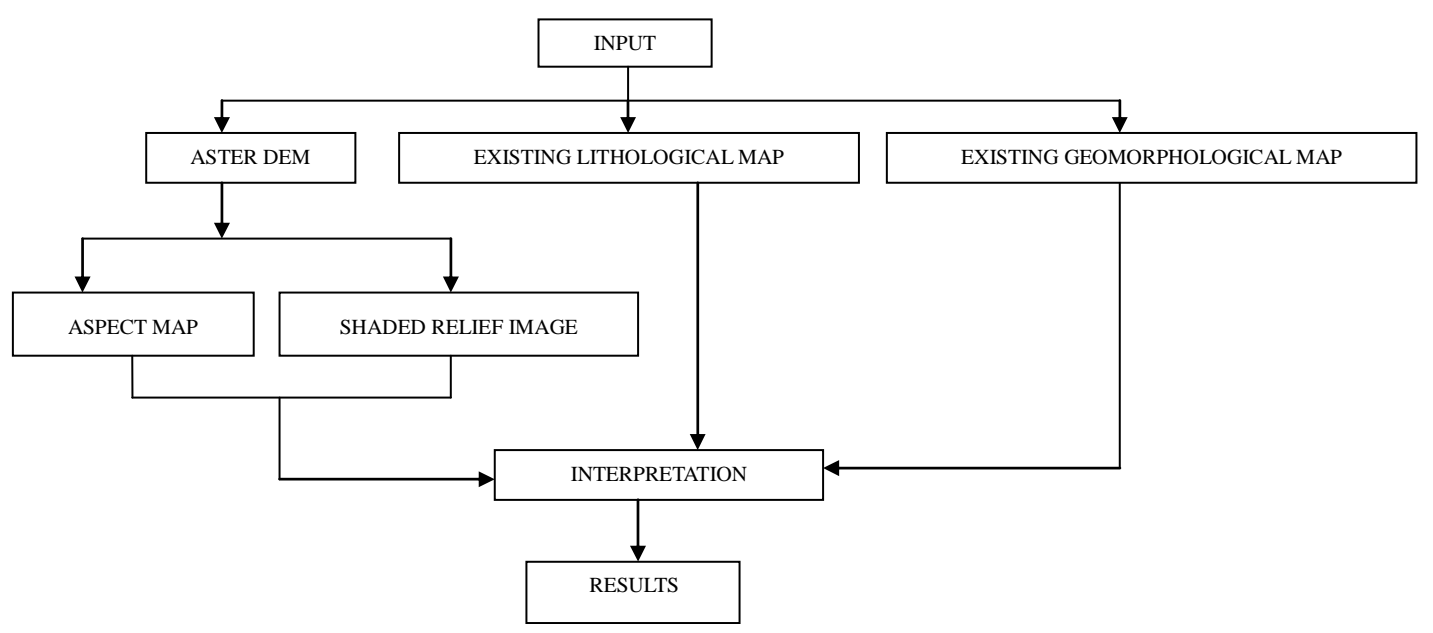

Figure 2. Flowchart showing methodology

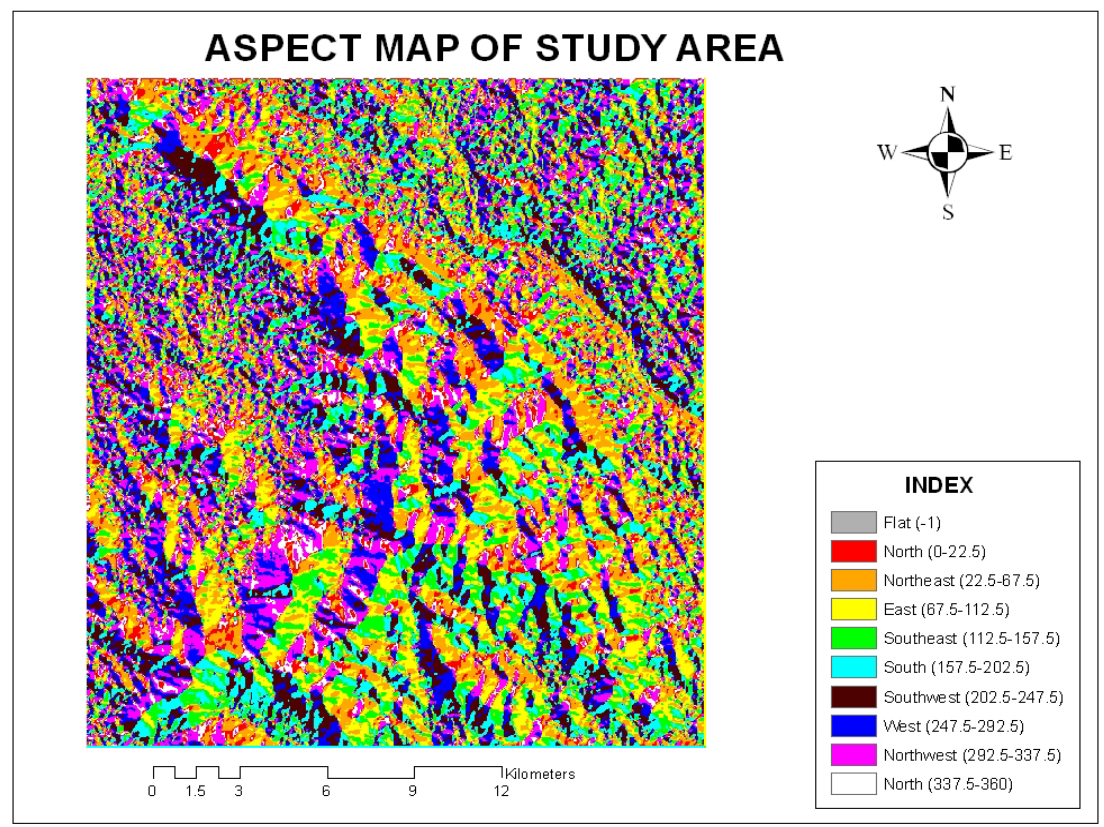

Figure 3. Aspect Map of study area

azimuth help in enhancing different features. On these parameters the various interpretations are made based on the shaded relief images, aspect map with reference to the existing geomorphological and lithological maps. The results are hereby presented in this paper (Figure 2).

\section{Data Interpretation}

Shaded relief images can help in extracting information about geomorphology, rock types and structure of an area. From the shaded relief image, the morphology which is described as extent, size, shape, height, variation of slope and aspect on the surface can be identified. Geological structures look curvilinear or linear on an image, out of which the curvilinears may indicate dome structures and the linears may indicate faults (Lillesand et al.1979)

In the present study, aspect map of the study area is prepared from the ASTER DEM and the shaded relief images are enhanced by changing the sun angle, azimuth and height exaggeration in different images. Changes in texture and pattern are seen in different parts in different images after the enhancements. It also helps in enhancing the rock type and structures to a certain extent. The enhanced features observed when the sun angles and azimuth are changed are as follows-

1) The NW elongated and arcuate shaped hilly areas associated with faults are seen in the middle part of 
the images. (Figure 4 \& 5)

2) The NE-SW flowing water body on the NE side of the images indicates presence of lineaments. (Figure 4,6 \& 8)

3) The intermontane areas in the mid and southern part of the images with scattered hills indicate surface beds of the outcrops. (Figure 6,7 \& 8)

In the process of identifying the geology of the study area from the shaded relief images, an already prepared lithological map of the same area was referred to. Hilly

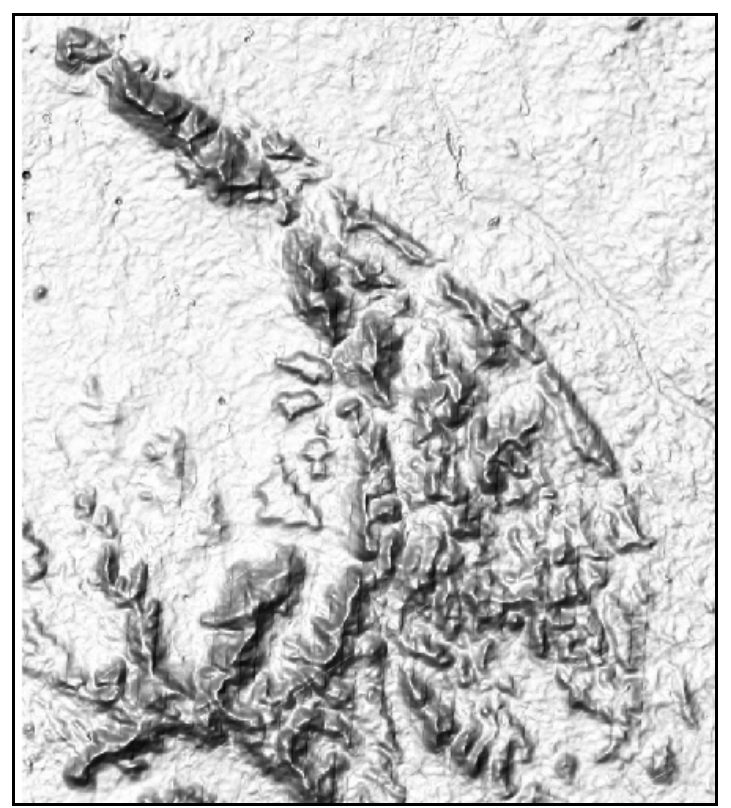

Figure 4. Shaded Relief Image (Azimuth 315, Sun angle75, Vertical exaggeration 5x)

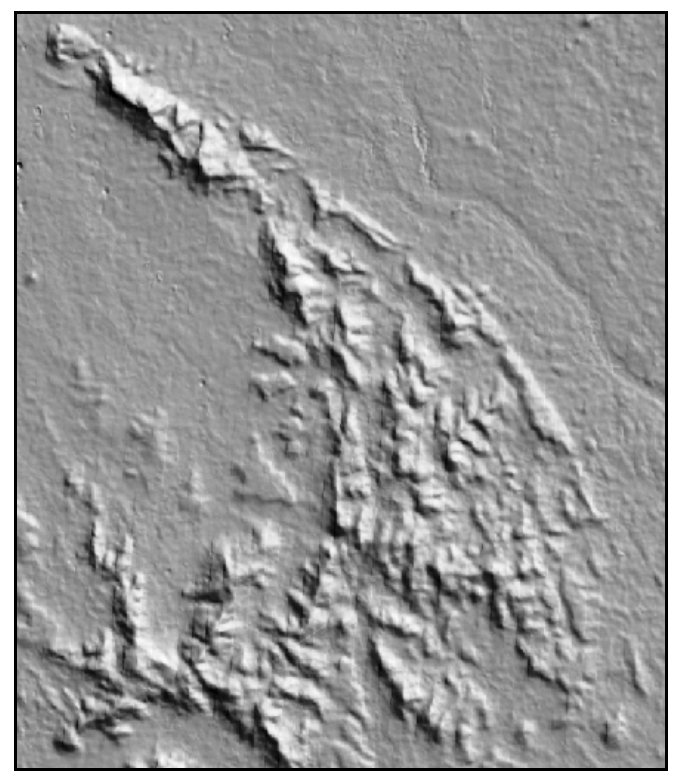

Figure 6. Shaded Relief Image (Azimuth 45, Sun angle45) range is found running diagonally across the study area in the shape of an arc and it is supposed to be made up of quartzites. To the NE portion of the hilly area lies a rugged topography without much drainage and without much change in slope and elevation. These are made up of metamorphic lithotypes of schists and phyllites. The SW portion of the study area seems to be made up of hard granitic rocks due to the texture and its association with the mountains. Intrusive rocks like dolerites are also supposed to be present in the intermontane valleys.

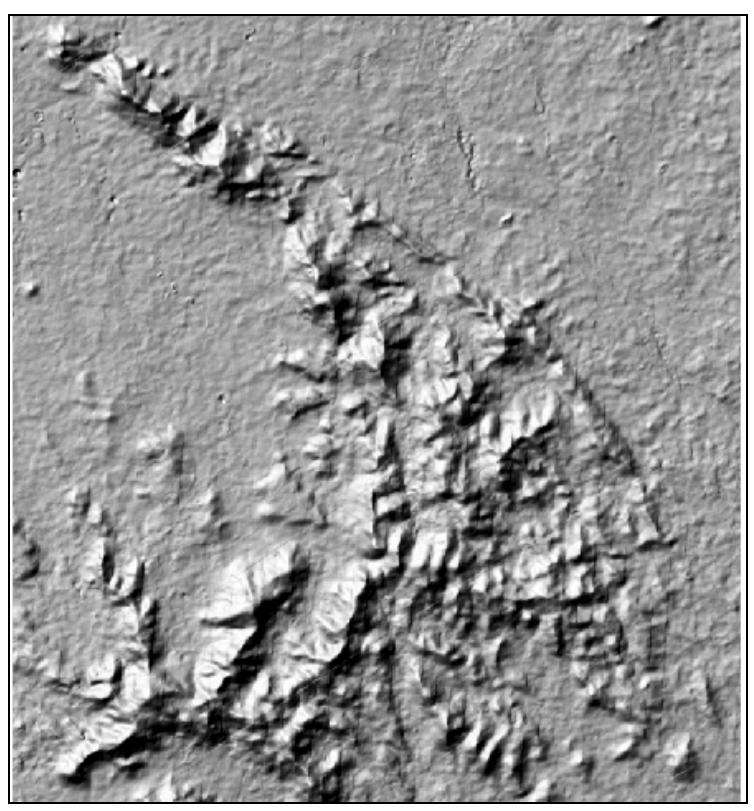

Figure 5. Shaded Relief Image (Azimuth 315,Sun angle 45, Vertical exaggeration 3x)

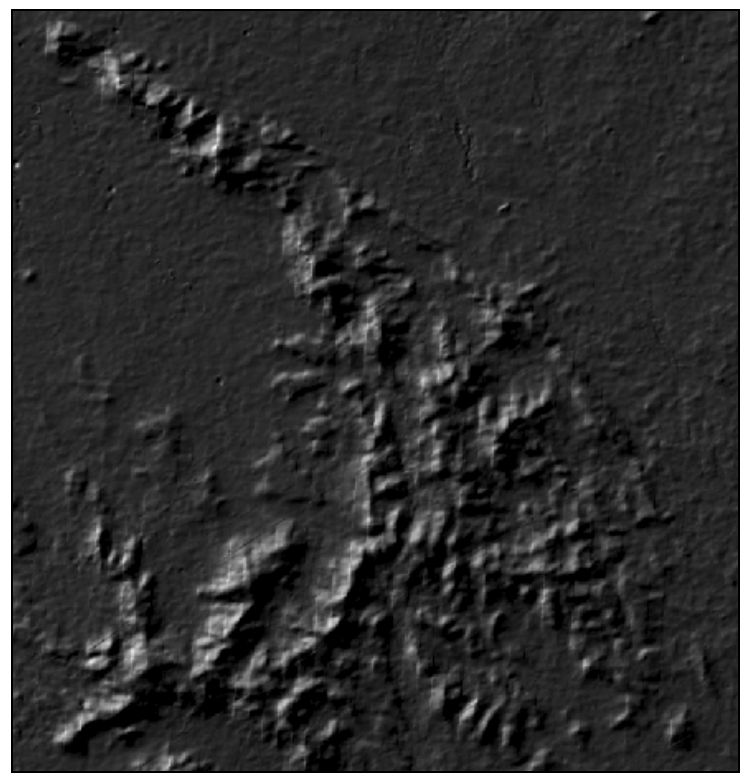

Figure 7. Shaded Relief Image (Azimuth 315,Sun angle10) 


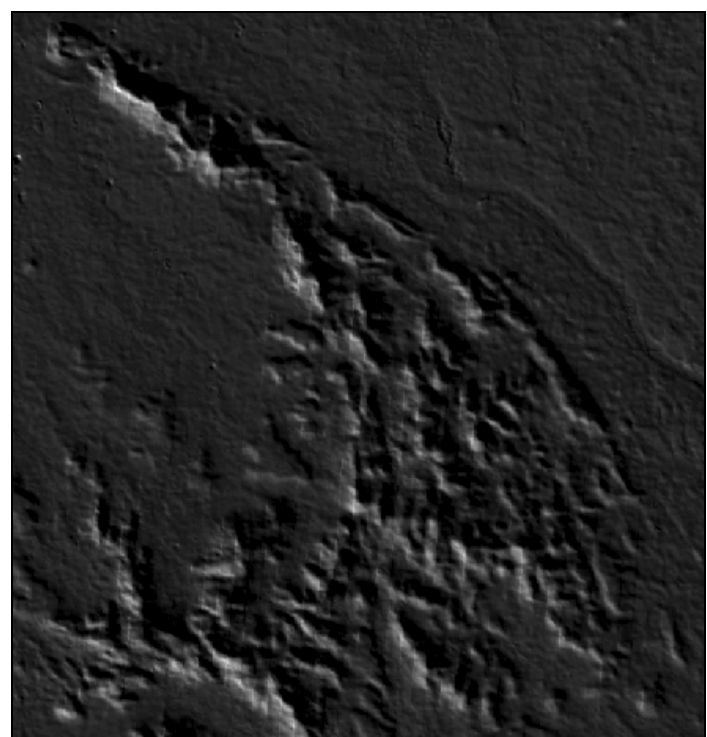

Figure 8. Shaded Relief Image (Azimuth 225, Sun angle10)

\section{Conclusion}

It is seen that DEM data can be used for geological interpretation in terms of geomorphology, materials and structure/ lineaments recognition but not to a very detailed level (Drury, 1987). It can be used for defining the structure, morphology etc of an area but as it lacks information like that of vegetation cover or soil moisture it cannot be trusted to give an accurate interpretation of the geology. DEM data, however cannot be ignored altogether as it can be very useful in giving an overview of the geology of any area especially where no other data is available for study. It can also prove to be a reliable source of supplementary datatabase in the visual interpretation as far as Remote Sensing and GIS is concerned. Reconnaissance survey before the interpretation can further help to identify the characteristic features seen through the imageries.
For better results an integrated datasets like topographical maps, aerial photographs, satellite data and ground data generated by previous workers can be highly useful.

\section{Acknowledgements}

This work has been carried out under the ISRO-SAC (RESPOND) Project (SAC Code: 0GP62, ISRO Code: 10/4/556), Department of Space, Govt. of India. We are thankful for the support provided by the Head of the Univ. Dept. of Geology, Ranchi University. We also thank Dr. A.T.Jeyaseelan, Director, JSAC for his kind motivation and co-operation. Dr. T.J.Majumder SAC focal person under the project is also gratefully acknowledged for his sharing and academic comments.

\section{REFERENCES}

[1] Drury, S.A., (1987) Image Interpretation in Geology, Allen \& Unwin, London.

[2] Gupta, R.P. (2003) Remote Sensing Geology $2^{\text {nd }}$ Edition. Springer, India.

[3] Lillesand, T.M., Kiefer, R.W., (1979) Remote Sensing and Image Interpretation, John Wiley and Sons, New York.

[4] Lo, C.P., Yeung, A.K. (2002) Concepts and Techniques of Geographic Information Systems $1^{\text {st }}$ Edition, Prentice Hall, India.

[5] Ostaficzuk, S (ed). (2005) The Current Role of Geological Mapping in Geosciences, Springer, Netherlands, pp.89-96.

[6] Sarapirome, S et.al (2002) Application of DEM data to Geological Interpretation: Tho Pha Phum Area, Thailand. 23rd Asian Conference on Remote Sensing, Birendra International Convention Centre, Kathmandu, Nepal.

[7] Singh, B, Dowerah, J.(2009) RS-GIS Based Strategies for Mineral Targetting in Parts of Singhbhum Shear Zone, Jharkhand.Vistas in Geological Research U.U. Spl. Publ. in Geology, Vol.8, pp. 81-86. 